Accepted Manuscript, Journal of the American Philosophical Association

\title{
Absence Causation for Causal Dispositionalists
}

\author{
Randolph Clarke \\ Florida State University \\ rkclarke@fsu.edu
}

In February 2017, the Secretary General of the United Nations warned of impending famine in northern Nigeria, Somalia, and Yemen. That same month, the UN declared famine in part of South Sudan. A New York Times article reporting the announcements asked, 'Why are people starving?’. It cited two reasons given by the Secretary General:

First, he said, there is not enough money; the United Nations needs $\$ 5.6$ billion to address the needs, most of it by the end of March. Barely 2 percent of that money is in hand.... Second, all four countries facing the threat of famine are reeling from conflict, and in many instances, the leaders of warring parties are blocking aid workers from delivering relief where it is most needed. (Sengupta 2017)

Other news articles identified drought as a contributing factor. ${ }^{1}$

If we think that absences can be causes and effects, we will see several examples of the phenomenon here. There is foreseen death due to lack of food: events caused, in part, by absence. A lack of rain has resulted in a lack of food production; and failures to contribute money pledged for relief have led to a lack of food relief — two examples of absence caused by absence. Finally, deliveries of food relief are being prevented by armed groups. Actions are causing absences, the non-occurrence of certain events.

\footnotetext{
${ }^{1}$ See, e.g., Gettleman (2017) and Mohamed and Chan (2017).
} 
Several accounts of causation rule out causation of or by lacks, omissions, or absences of things. Proponents of such views face a theoretical problem of characterizing the practical problem that I’ve recounted. I'll explore here how one such theory might be modified to deal with this theoretical challenge. The modification requires revising one of the main tenets of standard versions of the theory. But the revision leaves in place a fundamental commitment of the theory, while yielding better accord with what we commonly think and say about what causes what. The question to be considered is whether this general strategy is worth pursuing; to this purpose, only a sketch of the modified theory will be presented.

\section{Causal Dispositionalism}

The view of causation on which I'll focus is causal dispositionalism. ${ }^{2}$ We may see it as combining two theses, one about the nature of properties (or, at least, some of the fundamental ones-perhaps the natural or sparse properties, or at least some of these) and the other about causation. The first thesis claims:

(PP) Properties (at least some of the fundamental ones) are powers. ${ }^{3}$

The properties in question are said not to be categorical; they are essentially dispositional, they have modal essences. It is the nature of each that it is a power for some manifestation(s). Given the fundamentality of such properties, modality is a fundamental feature of the world. (If there is no fundamental level, there are powers “all the way down”.)

\footnotetext{
${ }^{2}$ Proponents include Heil (2012: ch. 6), Martin (2008: ch. 5), and Mumford and Anjum (2011). Molnar (2003: 18799) gestures toward a view of this kind, though he does not advance the thesis that I call CM (see below).

${ }^{3}$ Some causal dispositionalists (e.g., Mumford and Anjum [2011: 3]) hold that each of the properties in question is a cluster of powers. This detail won't matter to my discussion here.
} 
A standard version of the second thesis may be stated:

(CM) Causation is the manifestation of powers. ${ }^{4}$

CM might be advanced as a reductive analysis of causation (if the notions of power and manifestation are held to be more fundamental), or it might be said to exhibit an interconnection among equally fundamental notions (if the notions of power and manifestation are said to be themselves causally laden). ${ }^{5}$ In either case, it is supposed to tell us what causation, in any instance, consists in.

So understood, causal dispositionalism appears to rule out causation by absence. And, indeed, proponents often make the implication explicit. Stephen Mumford and Rani Lill Anjum, for example, declare: 'Causation by absence claims are false' (2011: 146). ${ }^{6}$ Causation of absences is apparently thought to be precluded as well, perhaps on the grounds that in any manifestation of powers, there is something that is an effect, whereas an absence isn't anything at all. ${ }^{7}$

The denial has a cost. We commonly believe and assert absence-causal claims—claims apparently citing absences of things as causes or effects. These figure in folk as well as scientific discourse, including that of physics, chemistry, biology, and psychology (Schaffer 2004: 202-3).

\footnotetext{
${ }^{4}$ I use 'manifestation' in this formulation as equivalent to 'manifesting'. When powers manifest, there is an outcome or effect, and 'manifestation' is sometimes used to refer not to the manifesting of the powers but to such an effect. CM would be worded somewhat differently on this second usage.

${ }^{5}$ Mumford and Anjum (2011: 7) present their view in the latter way; Heil (2012: ch. 6) seems to see things the first way.

${ }^{6}$ Heil takes a similar view: 'It is not that the absence produces, or is causally involved in the production of, the manifestation. Rather, properties on the scene yield a different, possibly unwelcome, kind of manifestation' (2012: 130).

${ }^{7}$ Mumford and Anjum (2011: 30) maintain that apparent causation of an absence is sometimes, in fact, production of an equilibrium state. This seems right for some cases (their examples concern states of stasis), but I doubt that it correctly characterizes others (in which the result might be a violent change).
} 
The position thus implies that much of what we commonly believe and say about what causes what is false. To the extent that what we believe and say about these matters reflects our concept of causation, there is a mismatch between that concept and what the theory says is the reality of the matter. Such a mismatch may lead us to suspect that whatever real phenomenon the theory might characterize, it doesn’t correctly characterize causation.

I'll consider two ways that causal dispositionalists can respond to this challenge. The first, which I'll discuss only briefly, is to downplay the significance of the conflict. The second response, to which I'll give more attention, is to revise CM in such a way that, while retaining a basic commitment of causal dispositionalism, we have a view that allows for causation of and by absences.

Before turning to the main discussion, let me briefly note two moves that I will not further consider. It might be said that expressions apparently referring to or quantifying over absences in fact refer to or quantify over ordinary, metaphysically unproblematic entities. For example, 'the non-occurrence of food deliveries' might be said to refer, on some occasion of its use, to certain ordinary events that actually occur in some spacetime region in which food deliveries are not taking place. There is no negativity (or other metaphysical peculiarity) in the entity in question; negativity resides only in an expression used to refer to it. (To treat absences in this way is to reify them reductively. ${ }^{8}$ ) Although I think that there are occasions on which claims of this sort are correct, they aren't generally so, and more often than not the expressions that we use when we talk of lacks, omissions, and absences don't refer to or quantify over any ordinary events, states, or properties. ${ }^{9}$ Second, it might be claimed that absences are beings in

\footnotetext{
${ }^{8}$ For example, by Lewis (2004: 282).

${ }^{9}$ In many cases, the salient candidates for metaphysically uncontroversial referents have causes or effects or other features that cannot be attributed to the absences. For elaboration of this point with respect to omissions, see Clarke (2014: 25-26).
} 
their own right, not ordinary events, states, or properties, but sui generis things that, necessarily, exist when and where their complements don't exist. (To treat absences in this way is to reify them nonreductively. ${ }^{10}$ ) Whatever one thinks about combinatorialism generally, one might find dubious this suggested necessary connection between distinct entities. The alternative on which I'll focus avoids it.

\section{Causal Explanation and Causation}

The first response to the challenge that I'll consider seeks to minimize the cost of denying that absences are causes or effects. As proponents of this strategy often argue, even if absences are not causes or effects, mentioning them-or, speaking more carefully, mentioning that certain kinds of thing are absent—can still serve to explain things, and commonly we can explain why this or that kind of thing is absent. Indeed, the argument goes, our explanations here can be causal.

Causal explanations, it is said, provide information about causal histories. Citing a cause of an outcome is one way of providing such information. Observing that the causal history of an outcome lacked an event of a certain kind is another way. Similarly, we can explain why no event of a certain kind occurred by citing causes of an outcome incompatible with the occurrence of any event of that kind. ${ }^{11}$

For example, it might be said that although lack of food does not cause famine deaths, such deaths occur because food is lacking. And although threats by armed groups do not cause lack of delivery of food relief, the threats can explain why no such delivery occurs.

\footnotetext{
${ }^{10}$ Lewis (2004: 281-82).

${ }^{11}$ For this view of causal explanation, see Lewis (1986). Beebee (2004) appeals to it in her rejection of absence causation.
} 
The explanatory claims can be backed by counterfactual claims, indeed counterfactuals of causation. If there had been sufficient food available, its consumption would have sustained life — an outcome incompatible with the deaths — and hence the deaths would not have occurred. ${ }^{12}$ If the armed groups had not threatened the relief convoys, causal processes that were interrupted would have continued, eventuating in the delivery of food relief. ${ }^{13}$

However, we commonly affirm and assert not just the explanatory claims, and not just the counterfactuals of causation, but the causal claims as well. Hence, if this is all that the causal dispositionalist has to offer, she still pays a high price. She might say that when people affirm and assert the absence-causal claims, they are confusing causal explanation with causation. No doubt people are confused about a lot of things. Still, this large a departure of the theory from what we commonly think and say raises a serious question about whether the theory provides an extensionally correct account of what we are thinking and talking about when we think and talk about causation. Can a causal dispositionalist do better?

\section{Derivative Causation}

The second response that I want to explore, to a greater extent, revises CM. The resulting theory then holds that not all causation is the manifestation of powers. The manifestation of powers, it says, is causation in its basic form. But besides this basic form, causation can take derivative forms. These can be characterized in terms of basic causation, and thus in terms of the manifestation of powers.

\footnotetext{
12 'If the cause is an absence, then to suppose away the cause counterfactually is not to attend to some remarkable entity and suppose it does not exist. Rather, we need only suppose that some unremarkable entity does exist' (Lewis 2004: 282-83).

${ }^{13}$ Mumford and Anjum (2011: 146) maintain that this-worldly powers are truthmakers of such causal counterfactuals. Eagle (2009) raises difficulties for an analysis of counterfactuals in terms of powers. Jacobs (2010) offers a powers semantics for counterfactuals.
} 
In developing this response, a causal dispositionalist might adopt parts of a strategy described (though eventually rejected) by David Lewis (2004). ${ }^{14}$ Lewis considers a causal functionalist analysis of causation, on which causation is said to be the relation that occupies a functional role specified by folk platitudes about causation. (For example, it might be taken as platitudinous that causation is an intrinsic relation between events that is, at least typically, associated with a probabilistic version of counterfactual dependence.) Observing that the analysis will not countenance causation of or by absences-it holds causation to be a relation, relations require relata, and an absence of an entity, Lewis maintains, is nothing at all—he recommends “retargeting” the analysis, taking it to define not causation but one variety of it, the basic variety.

Lewis gives the name 'biff' to whatever relation actually occupies the functional role in question, which he calls the biff-role. It is to be discovered a posteriori what this actual occupant is (and, indeed, whether there is one). Lewis speculates that it might be some relation familiar to physics, such as exerting a force upon, or transfer of energy or momentum; he would like, he says, to think that it is physical, at least fairly natural, and supervenient on local matters of particular fact. In any case, an event is said to directly cause another event just in case the first event stands in this relation to (just in case it biffs) the second.

No absence of an entity biffs or is biffed by anything. Nevertheless, Lewis suggests, varieties of causation of and by absences can be defined in terms of biff. I'll calls these further varieties derivative. Causation in these cases is not relational; it does not relate entities of any kind. It is nevertheless, Lewis maintains, genuine causation, as genuine as is biff.

Lewis suggests the following definitions of derivative direct causation:

\footnotetext{
${ }^{14}$ A slightly different way to modify causal dispositionalism is to repurpose Dowe's (2001) characterizations of what he calls "quasi-causation”, taking these to characterize varieties of derivative (but genuine) causation. I won't attempt to work out here which of these alternatives should be preferred, since my aim is to consider whether the more general strategy of allowing for varieties of derivative causation of and by absences is worth pursuing.
} 
The absence of any event of kind $C$ directly causes event $e$ iff, had there been an event $c$ of kind $C, c$ would or might have biffed some event $d$ incompatible with event $e$.

Event $c$ directly causes the absence of any event of kind $E$ iff $c$ biffs some event $d$ incompatible with any event of kind $E$.

The absence of any event of kind $C$ directly causes the absence of any event of kind $E$ iff, had there been an event $c$ of kind $C, c$ would or might have biffed some event $e$ of kind $E$. (Lewis 2004: 284-85) ${ }^{15}$

Indirect causation can be defined using the already defined notions of basic and derivative direct causation; it need not reduce to direct causation of either variety. For example, an event $c$ might directly cause an absence of any event of kind $D$, which absence in turn directly causes event $e$. It might then be the case that $c$ indirectly causes $e$, even if $c$ does not biff $e$.

Two of the moves suggested by Lewis, abstracted from the functionalist analysis he discusses, can be put to use by causal dispositionalists. What might be adopted are, first, retargeting an initial characterization of causation, taking it to characterize not causation but causation in its basic variety, and second, defining varieties of derivative direct causation in

\footnotetext{
${ }^{15}$ Why 'would or might' instead of just 'would'? The intention, apparently, is to allow for chancy causation. A causal dispositionalist wishing to pursue the suggested strategy will, I think, want to consider whether Lewis's formulation is best in this regard.
} 
terms of counterfactuals of basic causation (then defining indirect causation using the notions of basic and derivative direct causation).

Thus, the manifestation of powers, with actual entities as causes and effects, might be said to be causation in its basic form. Counterfactuals concerning powers-manifestation will then provide definitions of varieties of derivative direct causation involving absences. For example, the absence of an instantiation of a certain kind of power may be said to directly cause an effect $e$ iff had there been an instantiation of that kind of power, it would (or might—see note 15) have manifested in an effect incompatible with $e$. Lack of food causes famine deaths when, had food been available, its nutritive powers would have manifested in survival of the people in question.

Lewis raises two problems for the strategy of analysis that he describes. A causal dispositionalist adopting (just) the indicated parts of the strategy can, I believe, avoid the first problem and satisfactorily deal with the second.

First, as Lewis sees it, it as a contingent matter that biff occupies the functional role characteristic of causation. There are, he holds, worlds in which other relations occupy this role and thus count as basic causation in those worlds. There might be causation in worlds altogether lacking biff. Indeed, Lewis allows, there might be causation in worlds where nothing occupies the functional role in question. We have no assurance, then, that every possible variety of causation can be defined in terms of a functional analysis of biff. Thus, although Lewis accepts that truth values of causal claims in our and similar worlds supervene on biff, he rejects the idea that causation can be analyzed in this way.

Causal dispositionalists do not offer powers-manifestation as what, as a matter of contingent fact, occupies an analytically specified functional role. As I read them, they purport to characterize the nature of causation, to say what, necessarily, causation consists in. With their 
claim retargeted as suggested, it will be said that in any causal world, powers-manifestation is the basic variety of causation. If this is so, then any possible variety of derivative direct causation can be defined in terms of powers-manifestation, with indirect causation definable using the notions of basic and derivative direct varieties. No possible variety of causation will be left unreached by this strategy. Taken on its own terms, then, a modified causal dispositionalist theory avoids the first of the problems raised by Lewis.

The proposal nevertheless leaves us with a disjunctive theory of causation: causation is the manifestation of powers, or derivative variety 1 , or derivative variety 2 , or.... About such an account, Lewis asks (presenting the second problem), 'Why do we disjoin exactly these disjuncts? Why is the disjunction of just this long list of alternatives anything more than a miscellaneous gerrymander?' (2004: 286). ${ }^{16}$

Our concept of causation provides a rationale both for recognizing more than just the basic variety and for recognizing, as further varieties, all and only those countenanced by the suggested modified view. A rough articulation of the concept yields: causes are relevant to the probabilities of their effects; they can be evidence for predicting their effects, which can themselves be evidence for retrodicting their causes; causes can explain their effects; effects commonly counterfactually depend on their causes; and intervention to alter causal conditions can be a way of altering outcomes. ${ }^{17}$ When powers manifest, there are actual entities that satisfy these desiderata. Absences that are counted as causes or effects in derivative varieties of

\footnotetext{
${ }^{16}$ Stephen Kearns pointed out to me that a modified dispositionalist theory might in fact present us with a rather short list of disjuncts, completing its account with basic causation, three varieties of derivative direct causation involving absences, and the transitive closure of these four forms.

${ }^{17}$ Schaffer (2004: 198-99) appeals to satisfaction of these "connotations of causation" to support recognizing absence causation. The expression (as well as articulation of many of the connotations) comes from Mellor (1995: chs. 5-7).
} 
causation likewise satisfy them. The disjuncts of the resulting theory, then, are not an arbitrary miscellany; they are held together by a rationale stemming from our concept of causation.

Causal dispositionalists aim to characterize the metaphysics of causation. Still, the target is the extension of our concept of causation. Articulation of the concept is pertinent to assessing whether the theory hits its target, and it provides unity to the recognized variety of forms of causation.

In comparison with standard causal dispositionalism, the modified view sacrifices some theoretical simplicity. The gain is better fidelity to our concept of causation with a concomitant better agreement with common judgments about what causes what.

Against accepting causation of and by absences, Phil Dowe (2001) cites what he calls an "intuition of difference": we sense a difference in claims that cite absences as causes or effects, in comparison with causal claims that cite only events. Taking absences to be involved in what he calls quasi-causation, and not in genuine causation, provides a good explanation of this intuition of difference.

The proposed theory provides an explanation that strikes me as at least as good. There is a genuine difference between claims citing absences as causes or effects and causal claims that cite only events. The former concern derivative causation, whereas the latter can concern basic causation. This is a real difference, though not one between real causation and something that is not really causation, but rather one between the fundamental and the derivative.

The modified theory rejects the view that causation, in every instance, is the manifestation of powers. It holds this to be true not of causation but of causation in its basic variety. But it maintains, further, that every possible variety of causation can be characterized in 
terms of powers-manifestation. Powers and their manifestation remain center stage. A basic commitment of causal dispositionalism is thus retained.

\section{The Problem of Proliferation}

Any theory that accepts causation by absence faces the following problem: if we accept it, we seem forced to accept as true many causal claims that people commonly deny. For example, suppose that the United Kingdom failed to contribute what it had pledged for UN famine relief. The failure might be said to be a cause of some famine deaths, for (let us suppose) had the contribution been made, it would have causally contributed to outcomes incompatible with these deaths. But the same might be true of the Queen’s not contributing a large sum from her own assets, though she had not committed and was not expected to do so. Our theory might then tell us that the Queen's omission, too, was a cause of the deaths, something that we may well think is not so. Again, we encounter a conflict between what the theory implies and what people commonly think and say about what causes what.

Theorists who accept causation by absence have proposed several ways of dealing with this problem. Some absences may be ruled out as causes because they are disproportionate to the effects in question, ${ }^{18}$ or because they are normal or violate no salient norms, ${ }^{19}$ or because they are absences of events that occur only in distant possible worlds. ${ }^{20}$ I'll consider very briefly the alternative of accepting that all absences that satisfy the modified dispositionalist theory are indeed causes. $^{21}$

\footnotetext{
18 Dowe (2010) examines this strategy.

${ }^{19}$ McGrath (2005) and Thomson (2003) endorse strategies of these kinds.

${ }^{20}$ Beebee (2004) examines (and rejects) this strategy.

${ }^{21}$ Or, at least, all absences of possible things. As impossibilities are causally irrelevant, so their absences might be said to be.
} 
On this alternative, the mistake that we make when we deny, for example, that the Queen's omission caused some of the deaths is to confuse pragmatic infelicity with falsehood. There is good reason to think that in fact we do often confuse these things. And it may be said that it is more plausible that we often make this mistake than that we often make the kinds of mistakes that deniers of absence causation attribute to us, such as confusing explanatory claims with causal claims (Beebee 2004) or confusing something that is not causation-quasicausation-with genuine causation (Dowe 2001). A theory that accepts causation of and by absences, then, may still be said to be in an important respect superior to one that denies it, on the grounds that the kind of error that it must find common is more plausibly a common error. Whether this alternative is superior to those that, in one way or another, seek to be selective about which absences are recognized as causes can only be judged by comparison with workedout versions of selective approaches, something that I shall not attempt here. ${ }^{22}$

\footnotetext{
${ }^{22}$ Thanks to Rani Lill Anjum, Sara Bernstein, Stephen Kearns, Sam Murray, and Nat Stein for their comments on earlier versions of this paper. Thanks as well to an editor and a referee for this journal, and to an audience at the 2018 Eastern Division Meeting of the American Philosophical Association.
} 


\section{References}

Beebee, Helen. (2004) 'Causing and nothingness’. In John Collins, Ned Hall, and L. A. Paul (eds.), Causation and Counterfactuals (Cambridge, Mass.: MIT Press), pp. 291-308.

Clarke, Randolph. (2014) Omissions: Agency, Metaphysics, and Responsibility. New York: Oxford University Press.

Dowe, Phil. (2001) ‘A counterfactual theory of prevention and “causation” by omission’. Australasian Journal of Philosophy, 79, 216-26.

Dowe, Phil. (2010) 'Proportionality and Omissions’. Analysis, 70, 446-51.

Eagle, Anthony. (2009) 'Causal structuralism, dispositional actualism, and counterfactual conditionals’. In Toby Handfield (ed.), Dispositions and Causes (Oxford: Oxford University Press), pp. 65-99.

Gettleman, Jeffrey. (2017) 'Drought and war heighten threat of not just 1 famine, but 4'. New York Times, https://www.nytimes.com/2017/03/27/world/africa/famine-somalia-nigeriasouth-sudan-yemen-water.html.

Heil, John. (2012) The Universe As We Find It. Oxford: Clarendon Press.

Jacobs, Jonathan D. (2010) ‘A powers theory of modality: Or, how I learned to stop worrying and reject possible worlds'. Philosophical Studies, 151, 227-48.

Lewis, David. (1986) ‘Causal explanation’. In Philosophical Papers, Vol. 2 (New York: Oxford University Press), pp. 214-40.

Lewis, David. (2004) 'Void and object'. In John Collins, Ned Hall, and L. A. Paul (eds.), Causation and Counterfactuals (Cambridge, Mass.: MIT Press), pp. 277-90.

Martin, C. B. (2008) The Mind in Nature. Oxford: Clarendon Press.

McGrath, Sarah. (2005) 'Causation by omission: A dilemma’. Philosophical Studies, 123, 125- 
48.

Mellor, D. H. (1995) The Facts of Causation. London: Routledge.

Mohamed, Hussein and Sewell Chan. (2017) 'U.N. chief, visiting Somalia, pleads for aid to avert famine’. New York Times, https://www.nytimes.com/2017/03/27/world/africa /famine-somalia-nigeria-south-sudan-yemen-water.html.

Molnar, George. (2003) Powers: A Study in Metaphysics. Oxford: Oxford University Press.

Mumford, Stephen and Rani Lill Anjum. (2011) Getting Causes from Powers. Oxford: Oxford University Press.

Schaffer, Jonathan. (2004) 'Causes need not be physically connected to their effects: The case for negative causation’. In Christopher Hitchcock (ed.), Contemporary Debates in Philosophy of Science (Oxford: Blackwell), pp. 197-216.

Sengupta, Somini. (2017) 'Why 20 million people are on brink of famine in a "world of plenty”, New York Times, https://www.nytimes.com/2017/02/22/world/africa/why-20million-people-are-on-brink-of-famine-in-a-world-of-plenty.html?_r=0.

Thomson, Judith Jarvis. (2003) ‘Causation: Omission’. Philosophy and Phenomenological Research, 66, 81-103. 